\title{
HUBUNGAN ANTARA HASIL UAN SMP DENGAN PRESTASI BELAJAR PESERTA DIDIK SMA
}

\section{IIN NURBUDIYANI ${ }^{11}$, M. FATCHURAHMAN ${ }^{2)}$ DAN ENDANG SRI SUYATI ${ }^{1)}$}

\author{
1) Dosen Program Studi Pendidikan Ekonomi \\ 2) Dosen Program Studi Bimbingan dan Konseling \\ Fakultas Keguruan dan Ilmu Pendidikan Universitas Muhammadiyah Palangkaraya
}

Email : iin_nurbudiyani@yahoo.co.id

\begin{abstract}
This research is aimed to find out: (1) The National Final Exam Result of Junior High School Students of Senior High School in 2011/2012; (2) Students' achievement of Senior High School in 2011/2012; (3) the relationship between The National Final Exam results of Junior High School and the learning achievement of Senior High School Students in 2011/2012. The technique analysis data used is: a) Percentege analysis technique, to achieving or obtaining the clarity about The National Final Exam results of Junior High School and learning achievement of students at $1_{\text {st }}$ and $2_{\text {nd }}$ semester; and b) Correlation techniques of product moment used to see how far the variables that are related to each other, and how far the correlation, among The National Final Exam results of Junior High School and Senior High School students. The result of this research was: (1) the first grade students at $1_{\text {st }}$ semester of Senior High School which have good exam results is relatively small, while the students which have less The National Final Exam result is relatively small also. Therefore it can be said that Senior High School students from The National Final Exam results of Junior High School is relatively quite enough; (2) The first grade students at $1_{\text {st }}$ semester of Senior High School which have good achievement is relatively small, while the students which have less achievement is relatively small also. Therefore it can be said that learning achievement of Senior High School students at $1_{\text {st }}$ semester is relatively quite enough; (3) the first grade students at $2_{\text {nd }}$ semester of Senior High School which have good achievement is relatively small, while the students which have less achievement is relatively small also. Therefore it can be said that learning achievement of Senior High School students at $2_{n d}$ semester is relatively quite enough; (4) There is significant relationship between The National Final Exam results of Junior High School and students at the $1_{s t}$ and $2_{n d}$ semester learning achievement of Senior High School students.
\end{abstract}

Keywords : relationship, the national final exam result, learning achievement, senior high school students.

\section{ABSTRAK}

Penelitian ini bertujuan untuk mengetahui: (1) Hasil UAN SMP peserta didik SMA tahun 2011/2012; (2) Prestasi belajar peserta didik SMA tahun 2011/2012; (3) Hubungan antara hasil UAN SMP dengan prestasi belajar peserta didik SMA tahun 2011/2012. Adapun teknik analisis data yang digunakan adalah: a) Tenik analisa Prosentase, untuk mencapai atau diperolehnya kejelasan tentang hasil UAN SMP dengan prestasi belajar peserta didik pada semester I dan II; dan b) Teknik korelasi Product Moment digunakan untuk melihat seberapa jauh variabel itu berhubungan satu sama lain, dan seberapa jauh korelasinya, yaitu antara hasil UAN SMP dengan prestasi belajar peserta didik SMA. Hasil penelitian adalah sebagai berikut: (1) Peserta didik kelas I semester I di SMA yang hasil UAN nya baik relatif sedikit, sedangkan peserta didik yang hasil UAN nya kurang juga relatif sedikit. Oleh karena itu dapat dikatakan bahwa peserta didik SMA hasil UAN SMP nya relatif cukup; (2) Peserta didik kelas I semester I SMA yang prestasi belajarnya baik relatif sedikit, sedangkan peserta didik yang hasil prestasi belajarnya kurang juga relatif sedikit. Oleh karena itu dapat dikatakan bahwa peserta didik SMA semester I hasil prestasi belajarnya relatif cukup; (3) Peserta didik kelas I semester II SMA yang prestasi belajarnya baik relatif sedikit, sedangkan peserta didik yang hasil prestasi belajarnya kurang juga relatif sedikit. Oleh karena itu dapat dikatakan bahwa peserta didik SMA semester II, hasil prestasi belajarnya relatif cukup; (4) Ada hubungan yang signifikan antara hasil UAN SMP dengan prestasi belajar peserta didik pada semester I dan II, pada peserta didik di SMA.

Kata kunci: hubungan, hasil Ujian Akhir Nasional (UAN), prestasi belajar, peserta didik SMA 


\section{PENDAHULUAN}

Dalam rangka untuk mewujudkan cita-cita bangsa yaitu mencerdaskan kehidupan bangsa, maka pendidikan merupakan salah satu program pemerintah yang harus dilaksanakan. Pendidikan adalah usaha sadar untuk mengembangkan kepribadian dan kemampuan di dalam dan di luar sekolah yang berlangsung seumur hidup. Perkembangan ilmu pengetahuan dan teknologi tidak terbendung lagi, begitu cepat dalam perkembangannya. Titik berat pembangunan pendidikan diletakkan pada peningkatan mutu dan perluasan daerah pendidikan dasar dalam mewujudkan dan memantabkan pelaksanaan wajib belajar. Dalam rangka meningkatkan dan meratakan mutu pendidikan, pemerintah melalui Departemen Pendidikan Nasional telah menyelenggarakan ujian faktor yaitu Evaluasi Belajar Tahap Akhir Nasional (EBTANAS), yang mulai tahun 2004 disebut dengan UAN. Dengan dilaksanakannya UAN maka proses belajar mengajar di sekolah didorong untuk benar-benar diselenggarakan sesuai dengan kurikulum, buku, alat peraga/praktek yang telah ditetapkan. UAN merupakan umpan balik secara nasional, sehingga berdasarkan umpan balik itu dapat diambil tindakan-tindakan untuk meningkatkan dan memeratakan pendidikan.

Berdasarkan Keputusan Direktorat Jendral Pendidikan Dasar dan Menengah, Departemen Pendidikan Nasional No: 139-140/C/Kep I/1984 tertanggal: 1 September 1984, tentang pedoman pelaksanaan EBTA dan EBTANAS bagi sekolah dalam lingkungan pembinaan Dirjen Dikdasmen Depdiknas, dikemukakan tentang pelaksanaan EBTA/EBTANAS sebagai berikut:
Sekolah negeri dan swasta dalam lingkungan pembinaan Dirjen Dikdasmen Depdiknas menyelenggarakan EBTA/ EBTANAS untuk kelas terahkir pada tahun ajaran. EBTA adalah suatu kegiatan penilaian melalui kemampuan siswa sesudah mengikuti suatu program belajar yang dilakukan sehari-hari dalam waktu tertentu. EBTA meliputi semua bidang studi yang diajarkan berdasarkan kurikulum yang berlaku. Sedangkan EBTANAS diselenggarakan oleh tingkat nasional secara bertahap meliputi bidang studi: Bahasa Indonesia, Bahasa Inggeris, IImu Pengetahuan Alam (IPA), IImu Pengetahuan Sosial (IPS), dan Matematika. EBTA/EBTANAS diselenggarakan serentak bersama-sama ditangani oleh panitia penyelenggara EBTA/EBTANAS. Nilai EBTANAS dicantumkan dalam DANEM (Daftar Nilai EBTANAS Murni) yang menjadi dasar untuk mendapatkan nilai STTB serta pedoman syarat mutlak untuk mendaftarkan ke SMTA. Pendaftaran dilakukan secara kolektif dengan faktor rayonisasi diurus dan ditangani oleh sekolah yang bersangkutan.

Dengan adanya keputusan tersebut di atas mempunyai dan menentukan langkah-langkah untuk mengikuti pelajaran selanjutnya. Bagi yang mempunyai NEM tinggi akan memiliki prestasi yang tinggi dan peserta didik diharapkan dapat mengikuti dan menyelesaikan program studi di SMA dengan factor tanpa hambatan. Prestasi belajar adalah suatu kemajuan yang diperoleh peserta didik atau anak berupa informasi, kesimpulan, konsep ataupun nilai yang dapat diterapkan dalam situasi atau pengalaman baru, pergaulan dengan teman, perilaku di sekolah, di rumah ataupun di lingkungan tetangga/ masyarakat sekitarnya.

Dengan adanya pendapat tersebut di atas akan jelas dan bagaimana dampak UAN SMP terhadap prestasi belajar peserta didik di SMA. Berdasarkan uraian pada pendahuluan, rumusan 
masalah yang akan menjadi objek dalam penelitian ini adalah: 1) Bagaimana hasil UAN SMP bagi peserta didik di SMA tahun 2011/2012; (2) Bagaimana prestasi belajar bagi peserta didik di SMA tahun 2011/2012; (3) Adakah hubungan antara hasil UAN SMP dengan prestasi belajar bagi peserta didik di SMA tahun 2011/2012.

\section{Pengertian, Tujuan dan Kegunaan Evaluasi Belajar}

Evaluation vefer to the act or actor to determining the value of samething (Wayan Nurkancana, 2003: 1), bahwa evaluasi adalah suatu tindakan atau suatu proses untuk menentukan nilai dari sesuatu. Setiap kegiatan tentu dilaksanakan untuk mencapai tujuan tertentu. Evaluasi adalah suatu kegiatan dilaksanakan guna mendapatkan informasi terhadap perencanaan, pelaksanaan dan hasil suatu kegiatan, baik yang paling sederhana sampai pada kompleks. Evaluasi dan penelitian dalam kegiatan pendidikan dan pengajaran merupakan kegiatan kompleks yang melibatkan metode, personel, biaya, sarana dan prasarana, bimbingan, daya serap peserta didik atau hasil belajar dan sebagainya. Semua upaya yang dilakukan sebaik mungkin agar semua berjalan faktor atau berada pada kondisi optimal, untuk mencapai tujuan yang telah direncanakan dan ditetapkan seoptimal mungkin.

Tujuan pendidikan nasional merupakan tujuan jangka panjang yang harus didekati dengan tujuan lembaga atau tujuan institusional. Pada lembaga tersebut, tujuan institusional didekati dengan tujuan kurikuler yang ingin dicapai oleh setiap bidang studi yang tercantum dalam struktur program kurikulum masing-masing lembaga. Kegiatan untuk mencapai tujuan pendidikan dilaksanakan dalam proses belajar mengajar secara formal di kelas, pada jenjang sekolah tertentu. Untuk mengetahui keberhasilan proses belajar mengajar perlu dilakukan evaluasi belajar. Evaluasi belajar di sekolah sering disebut dengan tes sumatif yang telah diorganisir dan dilaksanakan serentak atau bersama-sama setiap menjelang akhir semester bagi tiap-tiap kelas. Sedangkan bagi kelas III SMP dilaksanakan menjelang akhir tahun ajaran dilaksanakan Evaluasi Belajar Tahap Akhir atau disebut juga UAS dan UAN. Hasil tes sumatif UAS dan UAN dituangkan dalam nilai yang menjadi standart menentukan, mengukur kemampuan daya serap peserta didik dalam mengikuti menyelesaikan program bidang studi yang ditetapkan dalam kurikulum. Adapun tujuan evaluasi belajar adalah sebagai berikut: (a) Memberikan umpan balik (feed back) kepada guru sebagai dasar untuk memperbaiki proses belajar mengajar dan mengadakan program perbaikan dan pengayaan bagi peserta didik; (b) Menempatkan peserta didik dalam situasi belajar mengajar yang tepat, sesuai dengan tingkat kemampuan atau karakteristik yang dimilikinya; (c) Mengenal latar belakang baik psikologis, fisik dan lingkungan bagi peserta didik yang mengalami kesulitan dalam belajar dan mendapatkan nilai rendah dalam mata pelajaran yang diampunya.

Tujuan UAN adalah: (a) Merintis terciptanya standart nasional dalam suatu pendidikan dasar dan menengah; (b) Menyederhanakan prosedur penerimaan peserta didik baru; (c) Mempercepat peningkatan dan pemerataan mutu pendidikan dasar dan menengah; (d) Mendorong tercapainya tujuan kurikulum; (e) Mendorong agar PBM 
dilaksanakan berdasarkan kurikulum, buku paket, dan alat tulis perangkat praktis yang telah ditetapkan. Sedangkan kegunaan evaluasi belajar adalah: (a) Menentukan nilai pada Surat Tanda Tamat Belajar (STTB); (b) Pendaftaran masuk sekolah yang lebih tinggi

\section{Prinsip-prinsip Penyelenggaraan Evaluasi Belajar}

Agar penyelenggaraan UAN dapat berjalan dengan faktor dan tertib dapat mencapai hasil yang objektif, maka perlu adanya prinsip-prinsip penyelenggaraan UAN yang harus dupatuhi, yaitu: (a) Sekolah yang telah ditetapkan oleh Kepala Kantor Depdiknas sebagai penyelenggara UAS, wajib menyelenggarakan UAN; (b) Rayonisasi, dengan ketentuan tingkat wilayah, jumlah peserta dan tingkat kesulitan transportasi atau komunikasi; (c) Pengawasan, dengan cara silang; (d) Pemeriksaaan, dengan cara silang dan dilakukan secara serentak dalam satu tempat; (e) Daftar Nilai UAN.

\section{Pengertian, Bentuk dan Faktor-faktor yang Mempengaruhi Prestasi Belajar}

Pengertian prestasi menurut kamus umum Bahasa Indonesia (1984: 768), adalah hasil yang telah dicapai (dilakukan, dikerjakan dan sebagainya). Sedangkan pengertian prestasi secara umum adalah hasil yang telah dicapai atau suatu kegiatan yang dilaksanakan dengan usaha yang sungguh-sungguh, sehingga memperoleh hasil yang menyenangkan dan hasil tersebut biasanya dinyatakan dalam bentuk angka atau nilai. Sedangkan belajar adalah aktifitas yang menghasilkan perubahan pada diri individu yang belajar, yang mana perubahan itu pada pokoknya didapatkannya kemampuan baru yang berlaku faktor selama dan perubahan itu terjadi karena usaha. Perubahan individu yang dimaksud disini adalah perubahan tingkah laku yang diharapkan sesuai dengan tujuan belajar yaitu hasil yang diperoleh setelah menyelesaikan pengalaman belajar. Dapat disimpulkan bahwa yang dimaksud dengan prestasi belajar adalah tidaklah hanya terpancang pada nilai yang telah diperolehnya, atau nilai raport saja, melainkan bukti keberhasilan usaha yang dapat dicapai individu dalam mencapai tujuan belajar atau tujuan pendidikan yang telah ditetapkan.

Dalam proses belajar mengajar yang menjadi harapan adalah agar anak didiknya memperoleh hasil dan nilai yang memuaskan dalam hasil belajarnya. Menurut Sumadi Soeryobroto, mengelompokkan faktor-faktor yang mempengaruhi proses dan hasil belajar menjadi 4 kelompok yaitu: (1) bahan atau hal yang harus dipelajari; (2) faktor lingkungan; (3) faktor instrumental; dan (4) kondisi individu si pelajar.

\section{METODOLOGI}

Populasi dalam penelitian ini adalah seluruh peserta didik kelas I sebanyak 5 kelas dengan jumlah 120 peserta didik. Jumlah populasi 5 kelas diambil semua dengan harapan agar penelitian ini diperoleh data yang cermat serta sesuai dengan tujuan penelitian. Jenis datanya adalah: data tentang UAN dan data tentang prestasi belajar. Sumber datanya adalah peserta didik kelas I yang naik ke kelas II semua jurusan, dan yang diteliti terbatas pada prestasi belajar peserta didik semester I dan II, yang diambil dari lager. Teknik pengumpulan data penelitian adalah: wawancara, observasi dan dokumentasi. 
Penelitian ini bertujuan untuk mengetahui dan menemukan ada tidaknya hubungan serta seberapa eratnya hubungan antara variabel yang diteliti. Adapun teknik analisis data yang digunakan adalah: a) Tenik analisa Prosentase, untuk mencapai atau diperolehnya kejelasan tentang hasil UAN SMP dengan prestasi belajar peserta didik pada semester I dan II; dan b) Teknik korelasi Product Moment digunakan untuk melihat seberapa jauh variabel itu berhubungan satu sama lain, dan seberapa jauh korelasinya, yaitu antara hasil UAN SMP dengan prestasi belajar peserta didik SMA Muhammadiyah-1 Palangkaraya. Sesuai dengan teknik pengolahan data pada penelitian ini, maka metode penginterpretasian data yang digunakan adalah: skala kualifikasi prosentase sperti Tabel 1.

Tabel 1. Skala Kualifikasi Prosentase

\section{HASIL DAN PEMBAHASAN}

Dalam hasil penelitian ini akan diuraikan tentang penyajian data, klasifikasi data, serta interpretasi data sebagai berikut:

\section{Penyajian Data}

Hasil UAN SMP $\left(X_{1}\right)$, dengan jumlah 5 (lima) bidang studi, dengan skala kualifikasi:
$30-34$
Baik
$25-29$
Cukup/Sedang
$20-24$
Kurang

Prestasi Belajar peserta didik $\left(Y_{1}\right)$, dengan jumlah bidang studi kelas I pada semester I dan II, dengan kualifikasi:
$8-9$
Baik
$6-7$
Cukup/Sedang
$4-5$
Kurang

\begin{tabular}{ccc}
\hline Skala Prosentase & Kualifikasi \\
\hline 81 & -100 & Banyak Sekali \\
61 & -80 & Banyak \\
41 & -60 & Cukup \\
21 & -40 & Sedikit \\
0 & -20 & Sedikit Sekali \\
\hline
\end{tabular}

\section{Analisa Prosentase}

Tabel 2. Tabulasi Frekuensi Prosentase Semester I

\begin{tabular}{cccccc}
\hline \multicolumn{2}{c}{$\begin{array}{c}\text { Variabel } \\
\text { Kualifikasi }\end{array}$} & \multicolumn{2}{c}{$\mathrm{X}_{1}$} & \multicolumn{2}{c}{$\mathrm{Y}_{1}$} \\
\cline { 2 - 6 } & $(3)$ & $\mathrm{f}$ & $\%$ & $\mathrm{f}$ & $\%$ \\
\hline Baik & $(2)$ & 90 & 20,8 & 9 & 7,5 \\
Sedang/Cukup & 5 & 75 & 110 & 91,7 \\
Kurang & $(1)$ & 120 & 4,2 & 1 & 0,8 \\
\hline \multicolumn{2}{c}{ Jumlah } & & 100 & 120 & 100 \\
\hline
\end{tabular}

Tabel 3. Tabulasi Frekuensi Prosentase Semester II

\begin{tabular}{|c|c|c|c|c|c|}
\hline \multirow{2}{*}{\multicolumn{2}{|c|}{$\begin{array}{c}\text { Variabel } \\
\text { Kualifikasi }\end{array}$}} & \multicolumn{2}{|c|}{$\mathrm{X}_{1}$} & \multicolumn{2}{|c|}{$Y_{1}$} \\
\hline & & $\mathrm{F}$ & $\%$ & $f$ & $\%$ \\
\hline Baik & (3) & 24 & 20 & 32 & 26,7 \\
\hline Sedang/Cukup & (2) & 91 & 75,8 & 86 & 71,7 \\
\hline Kurang & (1) & 5 & 4,2 & 2 & 1,6 \\
\hline Jum & & 120 & 100 & 120 & 100 \\
\hline
\end{tabular}


Tabel 4. Tabulasi Frekuensi Prosentase Semester I dan II

\begin{tabular}{|c|c|c|c|c|c|}
\hline \multirow{2}{*}{\multicolumn{2}{|c|}{$\begin{array}{c}\text { Variabel } \\
\text { Kualifikasi }\end{array}$}} & \multicolumn{2}{|c|}{$\mathrm{X}_{1}$} & \multicolumn{2}{|c|}{$Y_{1}$} \\
\hline & & $\mathrm{F}$ & $\%$ & $f$ & $\%$ \\
\hline Baik & (3) & 25 & 20,8 & 9 & 7,5 \\
\hline Sedang/Cukup & (2) & 90 & 75 & 111 & 92,5 \\
\hline Kurang & (1) & 5 & 4,2 & - & - \\
\hline Jum & & 120 & 100 & 120 & 100 \\
\hline
\end{tabular}

\section{Analisa Korelasi}

a. Koefisien Korelasi Product Moment Hasil UAN SMP Dengan Prestasi Belajar Pada Semester I

$$
\text { Rumus: } \frac{X_{1} \times Y_{1}}{\sqrt{X_{1}^{2} \times Y_{1}^{2}}}: \frac{161,5}{\sqrt{613 \times 295,92}} \quad: 0,379
$$

b. Koefisien Korelasi Product moment Hasil UAN SMP Dengan Prestasi Belajar Pada Semester II

$$
\text { Rumus: } \frac{X_{1} \times Y_{1}}{\sqrt{X_{1}^{2} \times Y_{1}^{2}}} \quad: \frac{396,5}{\sqrt{501 . \times 243,80}} \quad: 1,134
$$

c. Koefisien Korelasi Product moment Hasil UAN SMP Dengan Prestasi Belajar Pada Semester I dan II

$$
\text { Rumus: } \frac{X_{1} \times Y_{1}}{\sqrt{X_{1}^{2} \times Y_{1}^{2}}} \quad: \frac{292,4}{\sqrt{505 \times 183,15}} \quad: 0,961
$$

\section{Pembahasan}

Sebelum mengadakan pengujian hipotesa perlu diketahui bahwa Ho tidak ada hubungan antara variabel $X$ (hasil UAN SMP) dengan variabel $Y$ (Prestasi belajar peserta didik semester I dan II). Sedangkan $\mathrm{H}_{1}$ ada hubungan antara variabel $X$ dan $Y$. Hal tersebut ditolak jika harga $r$ sama atau melebihi harga kritik ( $r$ kritik). Dengan demikian untuk menguji hipotesa, apakah ada hubungan atau tidak maka tinggal membandingkan antara $r$ hitung dengan $r$ kritik, pada taraf signifikansi $50 \%$ dengan $\mathrm{N}=120$ adalah 0,094.

a. Hasil hitungan antara hasil UAN SMP dengan prestasi belajar peserta didik pada semester I. Sesuai dengan analisa data, maka diperoleh $r$ hitung sebesar 0,379, maka $r$ kritik sebesar 0,094, Ho di tolak $\mathrm{H}_{1}$ di terima karena $r$ hitung lebih besar dari $r$ kritik. Dengan demikian dapat disimpulkan bahwa ada hubungan antara hasil UAN SMP dengan prestasi belajar peserta didik pada semester I dengan taraf signifikan $50 \%$.

b. Hasil hitungan antara hasil UAN SMP dengan prestasi belajar peserta didik pada semester II. Sesuai dengan analisa data, maka diperoleh $r$ hitung sebesar 1,134, maka $r$ kritik sebesar 0,094, Ho di tolak $\mathrm{H}_{1}$ di terima karena $r$ hitung lebih besar dari $r$ kritik. Dengan demikian dapat disimpulkan bahwa ada hubungan antara hasil UAN SMP dengan prestasi belajar peserta didik pada semester II dengan taraf signifikan $50 \%$.

c. Hasil hitungan antara hasil UAN SMP dengan prestasi belajar peserta didik pada semester I dan II. Sesuai dengan analisa data, maka diperoleh $r$ hitung sebesar 0,961 , maka $r$ kritik sebesar 0,094 , Ho di tolak $\mathrm{H}_{1}$ di terima karena $r$ hitung lebih besar dari $r$ kritik. Dengan 
demikian dapat disimpulkan bahwa ada hubungan antara hasil UAN SMP dengan prestasi belajar peserta didik pada semester I dan II dengan taraf signifikan $50 \%$.

\section{KESIMPULAN}

a. Peserta didik kelas I semester I di SMA yang hasil UAN nya baik relatif sedikit $(20,8 \%)$, sedangkan peserta didik yang hasil UAN nya kurang juga relatif sedikit $(4,2 \%)$. Oleh karena itu dapat dikatakan bahwa peserta didik yang hasil UAN SMP nya relatif cukup (75\%).

b. Peserta didik kelas I semester I di SMA yang prestasi belajarnya baik relatif sedikit $(7,5 \%)$, sedangkan peserta didik yang prestasi belajarnya kurang tidak ada $(0,8 \%)$. Oleh karena itu dapat dikatakan bahwa peserta didik kelas I semester I, prestasi belajarnya relatif cukup $(91,7 \%)$.

c. Peserta didik kelas I semester II SMA yang prestasi belajarnya baik relatif sedikit $(26,7 \%)$, sedangkan peserta didik yang prestasi belajarnya kurang juga relatif sedikit $(1,6 \%)$. Oleh karena itu dapat dikatakan bahwa peserta didik kelas I semester II, prestasi belajarnya relatif cukup $(71,7 \%)$.

d. Peserta didik kelas I semester I dan II SMA yang prestasi belajarnya baik relatif sedikit $(7,5 \%)$, sedangkan peserta didik yang prestasi belajarnya kurang tidak ada $(0 \%)$. Oleh karena itu dapat dikatakan bahwa peserta didik kelas I semester I dan II, prestasi belajarnya relatif cukup $(92,5 \%)$. e. Ada hubungan yang signifikan $(0,379$ lebih besar dari harga kritik $r$ 0,094), antara hasil UAN SMP dengan prestasi belajar peserta didik pada semester I.

f. Ada hubungan yang signifikan (1,134 lebih besar dari harga kritik $r$ 0,094), antara hasil UAN SMP dengan prestasi belajar peserta didik pada semester II.

g. Ada hubungan yang signifikan $(0,961$ lebih besar dari harga kritik $r$ 0,094), antara hasil UAN SMP dengan prestasi belajar peserta didik pada semester I dan II.

\section{DAFTAR PUSTAKA}

Anas Sudjono. 2006. Pengantar Evaluasi Pendidikan. Jakarta: PT Raya Grafindo Persada.

2008. Pengembangan Perangkat Penilaian Kognitif. Jakarta: Depdiknas.

2008. Pengembangan Perangkat Penilaian Afektif. Jakarta: Depdiknas.

. 2008. Pengembangan Perangkat Penilaian Psikomotor. Jakarta: Depdiknas.

Djemari Mardapi. 2008. Tehnik Penyusunan Instrumen Tes dan Non Tes. Yogyakarta: Mitra Cendekia.

Nasution. 2010. Kurikulum dan Pengajaran. Jakarta: PT Bumi Aksara.

Sumadi Suryabrata. Evaluasi Pendidikan. Jakarta: CV. Rajawali.

Sutrisno Hadi. 1996. Metodologi Research I. Yogyakarta: Andi Ofset.

Wayan Nurkencono. 2003. Evaluasi Pendidikan. Surabaya: Usaha Nasional.

WJS Poerwodarminto. 1984. Kamus Umum Bahasa Indonesia. Jakarta: PT Balai Pustaka. 